\title{
Assessing tsunami vulnerability, an example from Herakleio, Crete
}

\author{
M. Papathoma ${ }^{1}$, D. Dominey-Howes ${ }^{2}$, Y. Zong ${ }^{3}$, and D. Smith ${ }^{4}$ \\ ${ }^{1}$ Coventry Centre for Disaster Management, School of Sciences and the Environment, Coventry University, Coventry, CV1 \\ $5 \mathrm{FB}, \mathrm{UK}$ \\ ${ }^{2}$ Risk Frontiers, Department of Physical Geography, Macquarie University, North Ryde, NSW 2109, Australia \\ ${ }^{3}$ Department of Geography, University of Durham, DH1 3LE, UK \\ ${ }^{4}$ Centre for Quaternary Research, Division of Geography, School of Sciences and the Environment, Coventry University, \\ Coventry, CV1 5FB, UK
}

Received: 17 September 2002 - Accepted: 28 October 2002

\begin{abstract}
Recent tsunami have caused massive loss of life, destruction of coastal infrastructures and disruption to economic activity. To date, tsunami hazard studies have concentrated on determining the frequency and magnitude of events and in the production of simplistic flood maps. In general, such maps appear to have assumed a uniform vulnerability of population, infrastructure and business. In reality however, a complex set of factors interact to produce a pattern of vulnerability that varies spatially and temporally. A new vulnerability assessment approach is described, that incorporates multiple factors (e.g. parameters relating to the natural and built environments and socio-demographics) that contribute to tsunami vulnerability. The new methodology is applied on a coastal segment in Greece and, in particular, in Crete, west of the city of Herakleio. The results are presented within a Geographic Information System (GIS). The application of GIS ensures the approach is novel for tsunami studies, since it permits interrogation of the primary database by several different end-users. For example, the GIS may be used: (1) to determine immediate post-tsunami disaster response needs by the emergency services; (2) to pre-plan tsunami mitigation measures by disaster planners; (3) as a tool for local planning by the municipal authorities or; (4) as a basis for catastrophe modelling by insurance companies. We show that population density varies markedly with the time of the year and that $30 \%$ of buildings within the inundation zone are only single story thus increasing the vulnerability of their occupants. Within the high inundation depth zone, $11 \%$ of buildings are identified as in need of reinforcement and this figure rises to $50 \%$ within the medium inundation depth zone. $10 \%$ of businesses are located within the high inundation depth zone and these may need to consider their level of insurance cover to protect against primary building damage, contents loss and business interruption losses.
\end{abstract}

Correspondence to: M. Papathoma

(cbx118@coventry.ac.uk)

\section{Introduction}

Tsunami may cause catastrophic loss of life, destruction of property and engineered structures and coastal infrastructure and lead to major economic and business interruption losses. Highly destructive tsunami were recorded at a number of locations during the 1990's: in Flores, Indonesia in 1992 (Tsuji et al., 1995), in Hokkaido, Japan in 1993 (Shuto and Matsutomi, 1995; Shimamoto et al., 1995) and in Papua New Guinea in 1998 (Goldsmith et al., 1999; Kawata et al., 1999). It is clear therefore, that tsunami may pose a significant hazard in a number of coastal areas of the world. Consequent to the United Nations International Decade for Natural Disaster Reduction (IDNDR), efforts were made to understand the mechanisms of tsunami generation, propagation and coastal run-up, to determine their frequency, magnitude and impacts in different locations and to develop mechanisms by which they may be detected and monitored (Hebenstreit, 2001). Disaster and emergency management agencies then integrate this information for the purposes of issuing tsunami warnings and for developing disaster management plans including (1) pre-planning appropriate response activities in order to minimise the disruption following an event including those events that allow a rapid response and recovery and; (2) preparing and mitigating the likely impacts of future events. Such activities will include risk assessments, public awareness and education programmes; identification of evacuation routes and safe zones; the construction of flood barriers and the development of planning regulations and construction codes. To do this effectively, they must have reliable and accurate information concerning the likely spatial and temporal characteristics and impacts of potentially damaging tsunami at different frequency-magnitude scales.

Greece and surrounding regions (Fig. 1) have long been affected by tsunami. More than 160 events have been catalogued for the last 3500 years (Papadopoulos, 2001). The potential impacts of future tsunami are likely to be much greater than in the past (Dominey-Howes, 2002). It is therefore germane to enquire to what level are selected coastal segments 


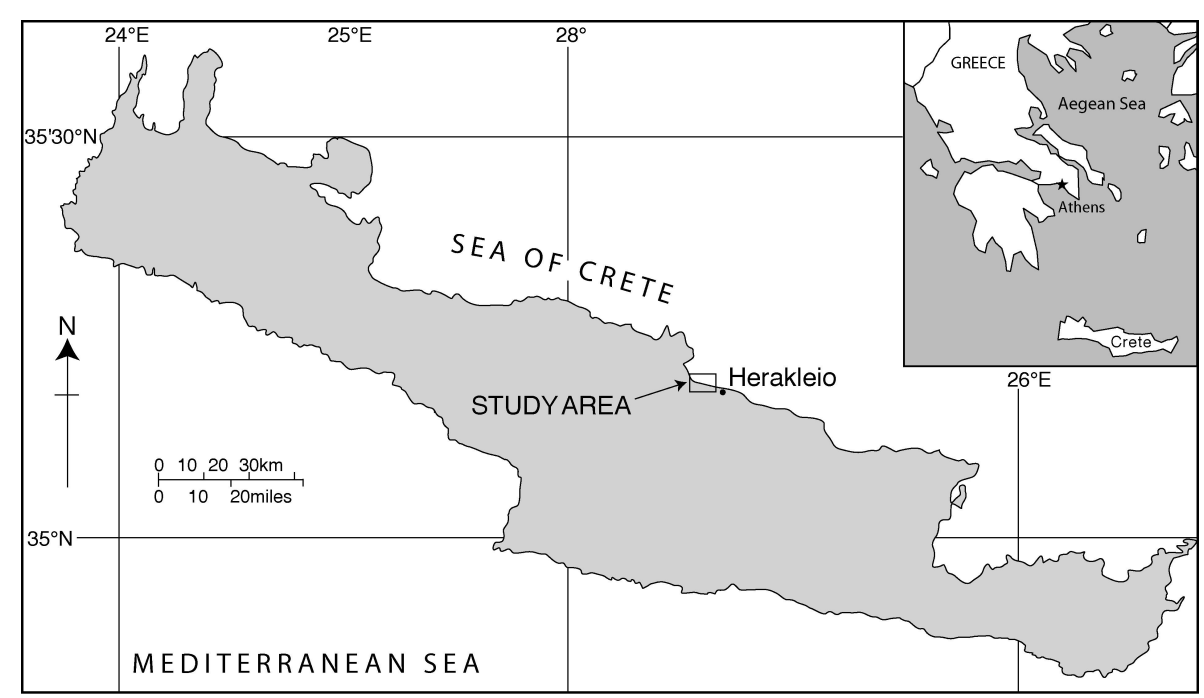

Fig. 1. The map of Crete and the study area.

of Greece at risk from and vulnerable to tsunami inundation and impacts.

\section{Background}

Tsunami vulnerability analysis is fundamental to effective disaster planning as, until a meaningful analysis has been undertaken, sensible mitigative measures cannot be developed fully or implemented effectively. Examination of tsunami risk maps (such as those that appear in telephone directories of coastal American cities or on the World Wide Web sites of the Federal Emergency Management Agency, USA and the Japan Meteorological Agency), indicate that tsunami flood risk (and therefore likely damage) is assumed to be uniform within the flood zone. Such maps show that all structures and people within this flood area are uniformly at risk of damage. While this appears to be the accepted approach, it should be clear that both the population and infrastructure within any given tsunami flood zone are not uniformly at risk. This is because risk (the probability for damage) is intimately related to vulnerability (the potential for damage) (Alexander, 2000) which in turn is a function of a number of parameters that include amongst others: distance from the shore, depth of flood water, construction standards of buildings, preparedness activities, socio-economic status and means, level of understanding and hazard perception and amount of warning and ability to move away from the flood zone. Therefore, a tsunami vulnerability analysis should be developed that includes as many of these factors as possible in order to gain a more realistic picture of spatial and temporal patterns of vulnerability. In this paper, we outline a new tsunami vulnerability assessment approach to do just this. Our approach is constructed and presented within a Geographic Information System (GIS) since tsunami vulnerability is spatially variable and a GIS helps to understand such variability once the base data have been compiled, alternative scenarios (hazard mag- nitudes) may be examined. GIS has been used in such analysis for several different hazard types (e.g. river and coastal floods, earthquakes, volcanic eruptions and hurricanes) and for integrated peril studies, but with few exceptions (e.g. Wood and Stein, 2001) has not been used for tsunami vulnerability analysis.

\section{Estimating tsunami hazard probability (return peri- ods) within Greece}

It is first necessary to establish the probability that a tsunami of a particular magnitude will occur within a given period of time and therefore, that tsunami pose a major hazard in Greece. Fortunately, during the last forty years or so, a number of authors have collated large amounts of data and have published catalogues for the eastern Mediterranean and Greek area (e.g. Antonopoulos, 1980; Papadopoulos, 1998; Soloviev et al., 2000). During the same period very detailed catalogues of earthquakes, which contain references to coincidental tsunami events, were compiled and published (e.g. Papazachos and Papazachou, 1997). From these catalogues it has been possible to calculate the probability (return periods) for different magnitude tsunami. From an analysis of these datasets, Papazachos and Papazachou (1997) and DomineyHowes (2002) report that tsunami in Greece and the surrounding areas with a maximum intensity or $K_{o}$ (on the Ambraseys-Sieberg six grade Intensity Scale (Ambraseys, 1962)) of III or larger, occur on average, every 4 years. The return periods of tsunamis with intensity IV or larger is 26 years, whereas tsunamis with intensity $\mathrm{V}$ or larger occur on average, every 170 years. Tsunamis with intensity VI or larger, have average return period of 1100 years. Of equal importance is an estimate of the likely wave height on-shore for tsunami of intensity III, IV, V and VI. Soloviev (1978) averaged wave heights for all known tsunami and determined maximum wave heights $\left(H(m)_{\max }\right)$ for intensity $\left(K_{o}\right)$ III as 
Table 1. Wave height according to Soloviev (1978) and according to Greek records for each grade of tsunami intensity and number of events per grade

\begin{tabular}{ccccc}
\hline $\mathrm{K}_{0}$ & $\begin{array}{c}\text { Wave height for each } \\
\text { tsunami intensity grade } \\
\text { according to Soloviev (1978) }\end{array}$ & $\begin{array}{c}\text { Wave height documented in } \\
\text { Greece and the } \\
\text { surrounding areas }\end{array}$ & $\begin{array}{c}\text { Return period } \\
\text { in Greece (years) }\end{array}$ & $\begin{array}{c}\text { Number of events } \\
\text { in Greece }\end{array}$ \\
\hline III & $+2 \mathrm{~m}$ & $+1 \mathrm{~m}$ & 4 & 55 \\
IV & $+4 \mathrm{~m}$ & $+5 \mathrm{~m}$ & 26 & 25 \\
$\mathrm{~V}$ & $+8 \mathrm{~m}$ & $+11 \mathrm{~m}$ & 170 & 10 \\
$\mathrm{VI}$ & $+16 \mathrm{~m}$ & $+20 \mathrm{~m}$ & 1100 & 2 \\
\hline
\end{tabular}

$+2 \mathrm{~m}$, for $K_{o} \mathrm{IV}$ as $+4 \mathrm{~m}$, for $K_{o} \mathrm{~V}$ as $+8 \mathrm{~m}$ and for $K_{o} \mathrm{VI}$ as $+16 \mathrm{~m}$. Since these calculations are more than twenty years old and relate to tsunami from all over the world, the mean $H(m)_{\max }$ for all tsunami ( $K_{o}$ III to VI) from the Greek area is calculated from the data of Papadopoulos (1998) which is the most complete dataset with 159 entries. It is calculated that the $H(m)_{\max }$ for intensity $\left(K_{o}\right)$ III is $+1.6 \mathrm{~m}$, for $K_{o}$ IV is $+4.8 \mathrm{~m}$, for $K_{o} \mathrm{~V}$ is $+11.5 \mathrm{~m}$ and for $K_{o} \mathrm{VI}$ is $+20 \mathrm{~m}$. As can be seen in Table 1, our values for $K_{o}$ III and IV are broadly similar to those of Soloviev (1978), but are somewhat larger for $K_{o} \mathrm{~V}$ and VI. This is due: (1) to a smaller dataset for the Greek area alone and (2) the presence of two very large tsunami in the near recent period skewing the data. These events are the AD1650 and the AD1956 tsunami. According to Papazachos and Papazachou (1997) and Papadopoulos and Chalkis (1984) the maximum wave heights for the specific events were 30 and $25 \mathrm{~m}$, respectively.

The data presented above are significant as they suggest that tsunami with a maximum wave height of $c .+5 \mathrm{~m}$ have a return period of as little as 26 years. Given that coastal areas of Greece have experienced significant development during the last 40 years in which no major tsunami has occurred, the probability for damage and insured losses is very high. It should also be noted that the last major $K_{o}$ VI tsunami occurred on 21 July AD365 (1637 years ago) associated with a large subduction earthquake beneath the Outer Hellenic Arc. Therefore, a major tectonic tsunami is long overdue. In addition, the north coast of Crete, which has been selected as the application region in this study, is characterised by the highest tsunamicity in Greece given that at least 15 tsunami events, four of them being destructive, were reported from antiquity up to the present. In Table 1 the number of tsunami events in each Intensity $\left(K_{0}\right)$ category is shown together with the expected (Soloviev, 1978) and recorded wave height in Greece.

\section{Previous work}

A number of authors have recognised the hazard probability that particular coastal areas of Greece face with regard to tsunami (Papazachos et al., 1986; Fritzalas and Papadopoulos, 1988; Fytikas et al., 1990; Dominey-Howes, 1998; Papadopoulos and Dermentzopoulos, 1998). The most com- prehensive tsunami risk analysis in Greece is the study of Papadopoulos and Dermentzopoulos (1998). These authors developed a "Tsunami Risk Management Pilot Study" for western Herakleio city, Crete. Their approach incorporates several steps: (1) collection and analysis of risk assessment parameters (e.g. natural environment, land use/land cover types, road network, functions and lifelines, socioeconomics and demographics); (2) qualitative description of a hypothetical tsunami and semi-quantitative description of probable tsunami impacts based on those parameters outlined in step 1 and; (3) the qualitative description of tsunami counter measures based upon a semi-quantitative description of expected impacts. The results of their investigation are presented in a series of 1:10000 hand-drawn thematic maps. The results were then presented using GIS (Ganas et al., 2001). The results of the tsunami risk analysis of $\mathrm{Pa}$ padopoulos and Dermentzopoulos (1998) are informative but problems arise in the application: (1) the results are based upon analysis of only 1 tsunami of a particular magnitude. If any other magnitude event were to occur, the likely impacts cannot be assessed from the thematic maps; (2) the semiquantitative approach described, is extremely complicated to follow and not easily transferred to other coastal locations and; (3) the methodology does not allow an assessment of potential impacts for a specific magnitude tsunami at different times of the day or year. That is, there is no temporal dimension to the analysis. The new approach presented in this paper solves these problems by using a database rather than a series of static maps.

\section{Research methodology}

\subsection{Approach and preliminary results}

In this section we describe the study area selected, the step by step process that has been completed during the development of our vulnerability analysis approach and, highlight some preliminary results. Data collection took place in July 2000.

\subsubsection{Step 1: Identification of field site}

In order to test the methodology, a representative coastal segment of Greece was selected. The western section of Herak- 
Table 2. Selected tsunamis known to have impacted Herakleio, Crete $(E R=$ earthquake, $V O=$ volcanic eruption $)$

\begin{tabular}{cclc}
\hline Date & Cause & Short description & Intensity $\mathrm{K}_{0}$ \\
\hline 1628BC & VO & Large wave in the eastern Mediterranean Sea & 6 \\
AD1303 & ER & Large destructive waves & 5 \\
AD1650 & VO & Large destructive waves & 6 \\
AD1956 & ER & Moderately destructive waves & 5 \\
\hline
\end{tabular}

Source: Papadopoulos (1998) and Papadopoulos and Chalkis (1984)

leio, Crete, was chosen because it has a developed urban infrastructure, a wide economic base and is an important centre of tourist activity. The area chosen also has a long historical record of tsunami floods and reliable information documenting specific tsunami wave heights and/or distances of inundation. Such information is a necessary first step in identifying likely inundation zones.

\subsubsection{Step 2: Estimation of worse case scenario}

Catalogues of historic tsunami were examined and those events that impacted the area of Herakleio were selected (Table 2). By collecting information about these events it was possible to identify the extreme inundation zone as the area between the coastline and the contour of the highest ever documented/recorded wave. In our study area the inundation zone is defined as the area between the coastline and the $5 \mathrm{~m}$ contour since this is the height of the largest recorded tsunami which occurred on 29 September AD1650 (Dominey-Howes et al., 2000). Therefore, the worse case scenario has a $H(m)_{\max }$ of $c .+5 \mathrm{~m}$ and correlates with a tsunami intensity of $K_{o}$ IV.

The purpose of this paper is not to consider physical mechanisms or hydrodynamic characteristics of tsunami during generation, propagation or inundation, but to identify and quantify the vulnerability to a hypothetical tsunami achieving a $+5 \mathrm{~m}$ wave height in a deterministic way. Therefore, we do not consider factors such as tsunami source region, direction of wave approach, off-shore bathymetry, coastal configuration, coastal geomorphology and hydrodynamic processes during inundation as these parameters are of concern more to theoretical modellers.

5.1.3 Step 3: Identification of parameters that may contribute to vulnerability

Since the vulnerability to tsunami damage and destruction is not uniform within the study area, a variety of parameters were identified and then information concerning each parameter was collected to generate the primary database. The information relating to each of these parameters was collected for each building or open space within the study area. It should therefore, be possible to determine spatial vulnerability and display temporal patterns depending on the scenarios being investigated. The parameters that we identify and take in to consideration are:

\section{The built environment}

Number of stories in each building:

- Only one floor (vertical evacuation is impossible).

- More than one floor (vertical evacuation is possible).

Here, the actual number of floors is not of interest. What does matter is whether there is the opportunity for vertical evacuation of the occupants. Therefore, where there is only one floor, the occupants are highly vulnerable to tsunami attack whereas, with two or more floors, occupants may vertically evacuate and as such, have a lower vulnerability.

Description of ground floor:

- Open plan with movable objects e.g. tables and chairs (high vulnerability to injury/damage).

- Open plan or with big glass windows without movable objects (moderate vulnerability).

- None of the above (low vulnerability).

Building surroundings:

- No barrier (very high vulnerability).

- Low/narrow earth embankment (high vulnerability).

- Low/narrow concrete wall (moderate vulnerability).

- High concrete wall (low vulnerability).

Building material, age, design:

- Buildings of fieldstone, unreinforced, crumbling and/or deserted (high vulnerability).

- Ordinary brick buildings, cement mortar, no reinforcement (moderate vulnerability).

- Precast concrete skeleton, reinforced concrete (low vulnerability).

Movable objects:

- Movable objects (objects considered moveable are those that can cause injuries to people, damage to 
buildings or block evacuation routes. Such objects include old cars, barrels, refrigerators, containers, construction materials and car components etc.) (high vulnerability).

- No movable objects (low vulnerability).

\section{Sociological Data}

Population density:

- Population density during the night.

- Population density during the day.

- Population density in the summer.

- Population density in the winter.

It would be preferable to have absolute figures for population density (i.e. people per building) but such data is not available for Greece. As such, we estimate relative population density for individual buildings and open spaces dependent upon their use. This is a useful technique since it may be applied to different study areas very easily.

Number of people per building:

- High or low (high or low vulnerability).

The National Census Office of Greece does not publish information on the absolute number of people per building (particularly residential units). However, depending on the number of units within a residential block, it is possible to estimate the average number of people. According to the European Commission (EC, 2000), the mean number of people per Greek household is 3 .

\section{Economic Data}

Land use:

- Business (shops, storage rooms, taverns, hotels, etc.).

- Residential.

- Services (schools, hospitals, power stations, etc.).

4. Environmental/Physical Data.

Physical or man-made barriers/sea defence:

- Natural (sandy beach or marsh) (low protection against flooding - high vulnerability).

- Soil embankment (moderate protection against flooding - moderate vulnerability).

- Concrete stone wall (high protection against flooding - low vulnerability).

Natural environment:

- Wide intertidal zone (high protection against flooding - low vulnerability).

- Intermediate intertidal zone (moderate protection against flooding - moderate vulnerability).
- Narrow intertidal zone (low protection against flooding - high vulnerability). It should be noted that Crete tidal range is minimal.

Land cover - vegetation:

- No vegetation cover (high vulnerability).

- Scrub and low vegetation (moderate vulnerability).

- Trees and dense scrub (low vulnerability).

The parameters we selected were chosen following an examination of tsunami impact surveys (e.g. Maramai and Tinti, 1997; Tsuji et al., 1995; Shuto and Matsutomi, 1995) and other risk/vulnerability studies of storm surge flooding; river flooding; earthquakes and volcanic eruptions (see Duncan et al., 1996; Fischer, et al., 1996; Synolakis et al., 1998; Bush et al., 1999; Camilleri, 1999; Solomon and Forbes, 1999).

5.1.4 Step 4: Establishing the GIS base map and generation of the primary database

A GIS operates by using two types of data: spatial data and attribute data. These data sets may then be combined in order to answer the questions being investigated.

1. Spatial data - the spatial data of the study area has to be digitised from an original topographic map or an air photograph in a scale that will allow the user to identify individual buildings and open spaces. A suitable scale is 1:5000. A 1:5000 1998 aerial photograph and a 1:5000 topographic map, both of which were supplied by the Greek Military Geographical Service, were used as base maps. The spatial data relates to each individual building, open space, road and stream.

2. Attribute data - the attribute data (the parameters) identified in Step 3 once collected, must be entered into the GIS. Tables for each attribute are established and linked to each building or open space in the spatial base map.

Attribute and spatial data were input into the GIS in the form of multiple coverages. A major advantage of our approach relates to the very fine scale at which primary data has been collected. In this study, the unit of data relates to an individual building or open space rather than to averaged blocks of buildings, cities or even entire regions. This means that high-resolution analyses may be performed. The data were collected during a ground based building-to-building survey where every unit was identified, coded and subject to assessment for each of the parameters listed in Sect. 5.1.3. Data were collected for 759 buildings.

\section{Results}

Analysis of the primary database according to different endusers (e.g. disaster planners, local authorities and insurance companies). 


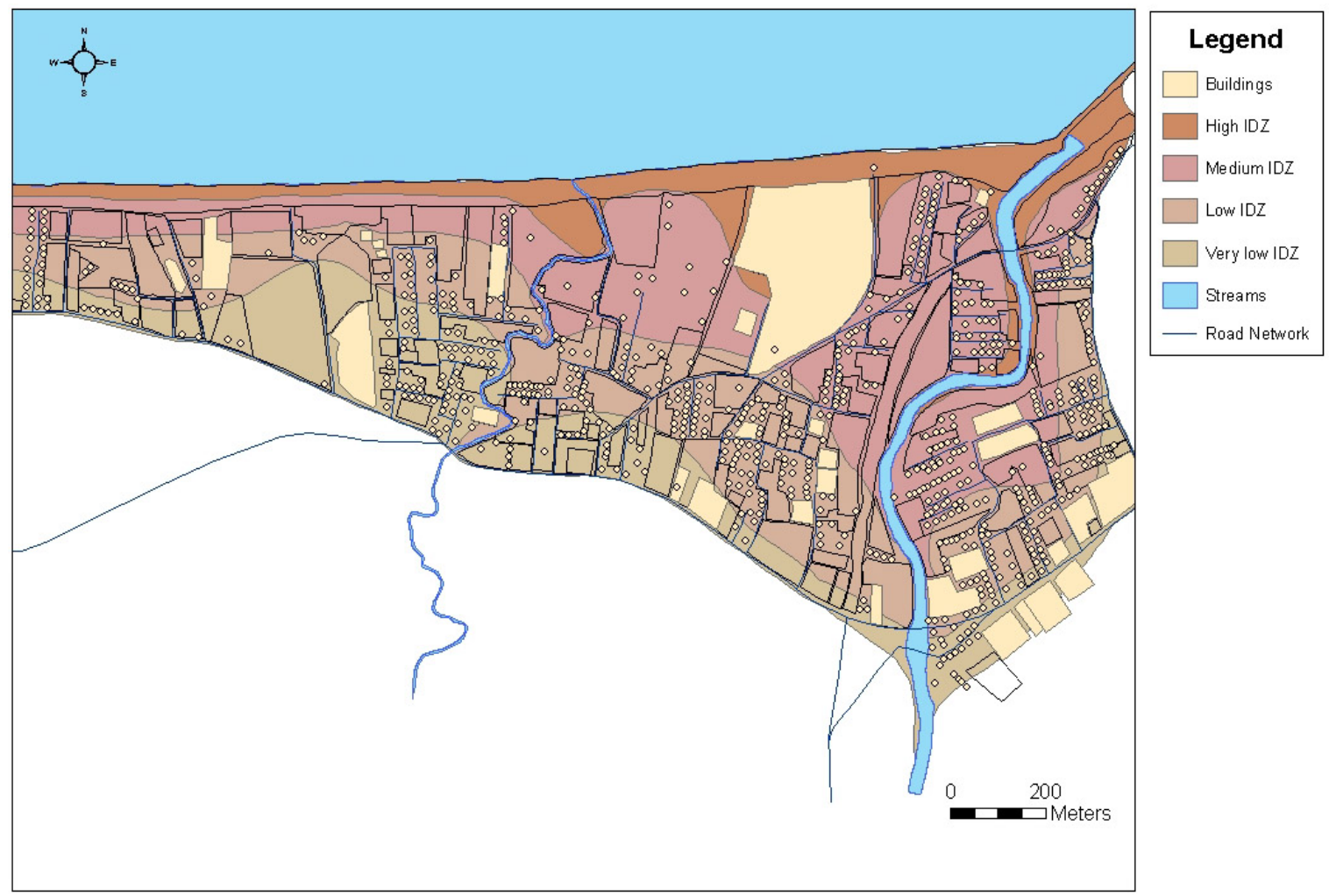

Fig. 2. The Inundation Depth Zones (IDZs) of the study area.

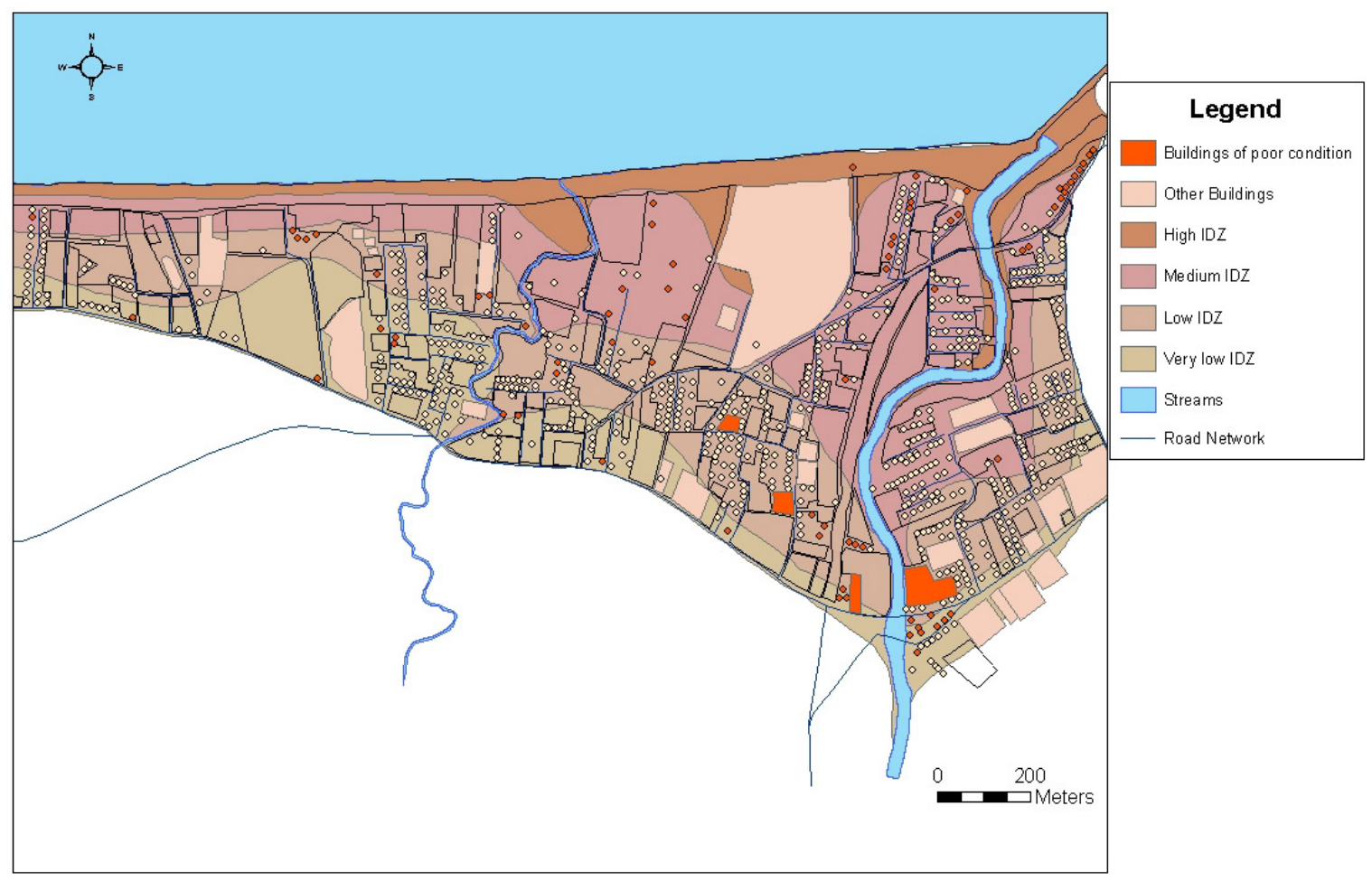

Fig. 3. Map showing the buildings of poor condition within the study area. 
Table 3. Thematic maps produced and list of input attribute data

\begin{tabular}{|c|c|c|}
\hline Thematic maps & Feature & Attribute data \\
\hline Road Network & Lines & - \\
\hline Rivers and streams & Lines & - \\
\hline Buildings & Points & $\begin{array}{l}\text { - Number of floors } \\
\text { - Condition of ground floor } \\
\text { - Use } \\
\text { - Population density during the day } \\
\text { - Population density during the night } \\
\text { - Population density during the summer } \\
\text { - Population density during the winter } \\
\text { - Number of residents } \\
\text { - Surroundings } \\
\text { - Natural Environment } \\
\text { - Sea defence }\end{array}$ \\
\hline $\begin{array}{l}\text { Open spaces and large units } \\
\text { (buildings that were too large } \\
\text { to be digitized as points) }\end{array}$ & Polygons & $\begin{array}{l}\text { - Number of floors } \\
\text { - Condition of ground floor } \\
\text { - Use } \\
\text { - Population density during the day } \\
\text { - Population density during the night } \\
\text { - Population density during the summer } \\
\text { - Population density during the winter } \\
\text { - Number of residents } \\
\text { - Surroundings } \\
\text { - Natural Environment } \\
\text { - Sea defence } \\
\text { - Movable objects }\end{array}$ \\
\hline
\end{tabular}

The primary database generated in Step 4 may be utilised by different end-users according to their particular requirements and a range of thematic maps may be generated from the primary database (Table 3 ). We envisage several endusers that might include:

- The Local Authorities - Fig. 2 shows tsunami inundation depth (ID) zones based on contour elevation. The inundation zone is divided in to four units: high, medium, low and very low inundation depth (ID). The high ID zone relates to the area from the coast to the $2 \mathrm{~m}$ contour. The medium ID zone lies between the $2 \mathrm{~m}$ and $3 \mathrm{~m}$ contours. The low ID zone lies between the $3 \mathrm{~m}$ and $4 \mathrm{~m}$ contours and the very low ID zone lies between the $4 \mathrm{~m}$ and $5 \mathrm{~m}$ contours. Local authorities may be interested in knowing which public and private buildings (e.g. homes, hospitals and schools) should be reinforced or even relocated because of their vulnerability to tsunami damage (Fig. 3). There are 78 buildings (approx. $10 \%$ of total housing stock) of poor condition within the inundation zone. From Fig. 3, it is clear that there are just a few houses of very poor condition within the high ID zone (4 buildings which is $5 \%$ of total housing stock) and may require reinforcement. A large amount of buildings of poor condition are located in the medium ID zone (40\%). The rest of the buildings of poor condition are located within the low and very low ID zones (33\% and $22 \%$ respectively). 26 of the buildings of poor condition within the inundation zone have no residents (33\% of the buildings of poor condition). Local authorities may also be interested in understanding the distribution of moveable objects which may be transported by a tsunami thus blocking access routes used by emergency personnel and vehicles so that a clean-up programme may be implemented (Fig. 4). From Fig. 4, it is apparent that the study area is characterised by the presence of a large number of buildings/open spaces where moveable objects are present. During the summer months, the coastal area is full of tables and chairs associated with cafes and restaurants. Local authorities may also want information that allows them to formulate planning regulations, direct building programmes and issue construction licences. The information associated with the various parameters in the primary database would allow the generation of a series of maps to address these needs.

- The Disaster Planners - Disaster managers and emergency planners will be interested in such questions as: which buildings are likely to contain large numbers of trapped and or injured survivors because there is no opportunity for vertical evacuation? Which buildings are likely to have a high population density and how will 


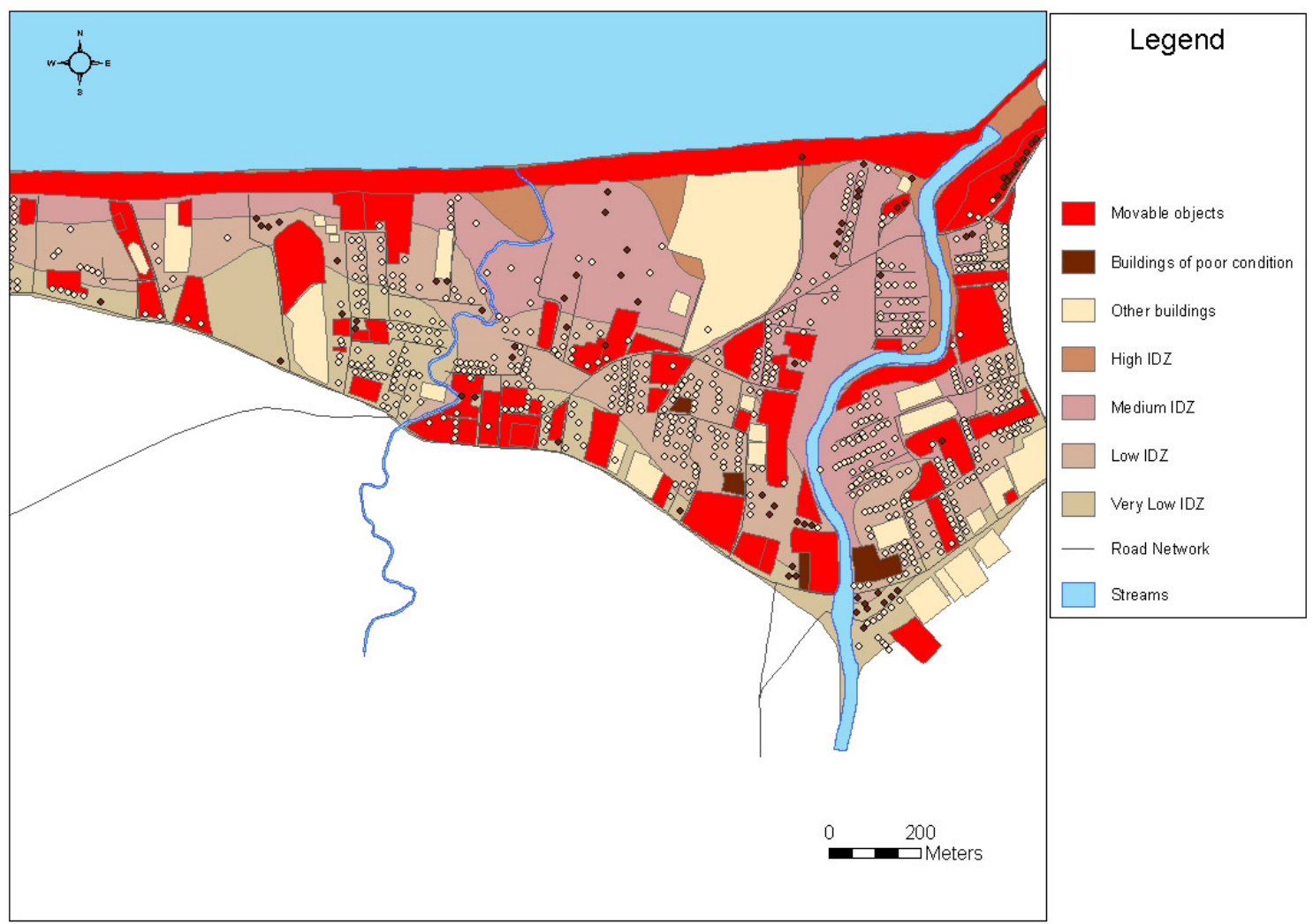

Fig. 4. The location of movable objects within the study area.

density change with time of year (e.g. hospitals and hotels) (Figs. 5 and 6)? By comparing Figs. 5 and 6, it is clear that during the summer the coast (open spaces, camping sites, hotels and restaurants) are densely populated. Disaster managers have to make sure that access roads to the beaches are not blocked. Conversely, during the winter, the same area has a very low population density. In the winter however, the highlighted buildings (schools and kindergartens) are densely populated and in the summer they are empty. Disaster managers will also be interested in knowing which buildings will have particularly vulnerable populations (e.g. schools, hospitals and nursing homes). Where should emergency shelters be located and which public access routes and roads should be selected for safe evacuation? Which buildings do not offer the opportunity for vertical evacuation? Figure 7 shows the locations of single story buildings and their proximity to the road network of the study area. Approximately $30 \%$ of all buildings within the inundation zone are single floor buildings and 11 of them are located more than $50 \mathrm{~m}$ from the road network. This means that a significant proportion of the population within the area are especially vulnerable. After any tsunami, the rescue teams should pay particular attention to these buildings, as they are where large numbers of casualties and dead may be located. The distribution of these buildings is generally random. The map also shows that not all the one-floor buildings have access to a road leading to higher ground. For this reason the buildings located in the northern part of the area between the two rivers are particularly vulnerable. Once again, the primary database may be interrogated to produce a series of thematic maps to investigate such questions.

- The Insurance Companies - Insurance companies will be interested in questions such as: what is the potential level of claims for a particular portfolio of insured assets in a specific location? What levels of premiums should be set for buildings, contents loss and business interruption loss insurance in particular areas (Fig. 8)? What would be the level and duration of business interruption losses that would have to be paid out in the event of a major tsunami (Fig. 9)? Figure 8 shows those buildings that are at a high risk of experiencing significant contents loss (158 buildings). This selection was based on a combination of the characteristics of buildings concerning the nature of the ground floor and the surroundings (Table 3). It is these buildings that are likely to make large insurance claims. However, from Fig. 8 it can be seen that there are not many buildings that fall in to this category. In Fig. 9 the distribution of businesses within each of the ID zones is shown. $10 \%$ of businesses are located within the high ID zone and as such are highly vulnerable to damage, contents loss and interruption to 


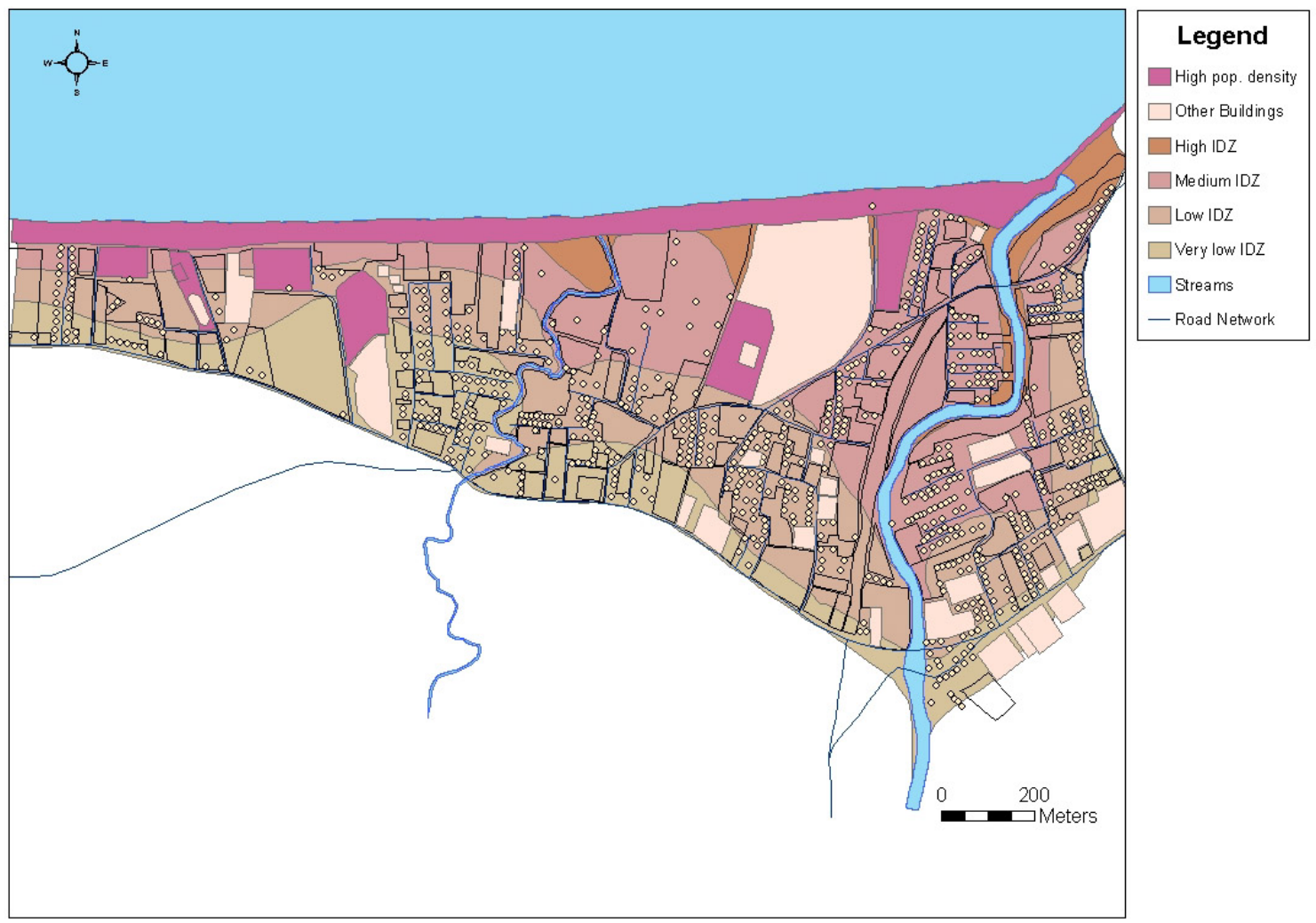

Fig. 5. The population density within the study area during the day in the summer.

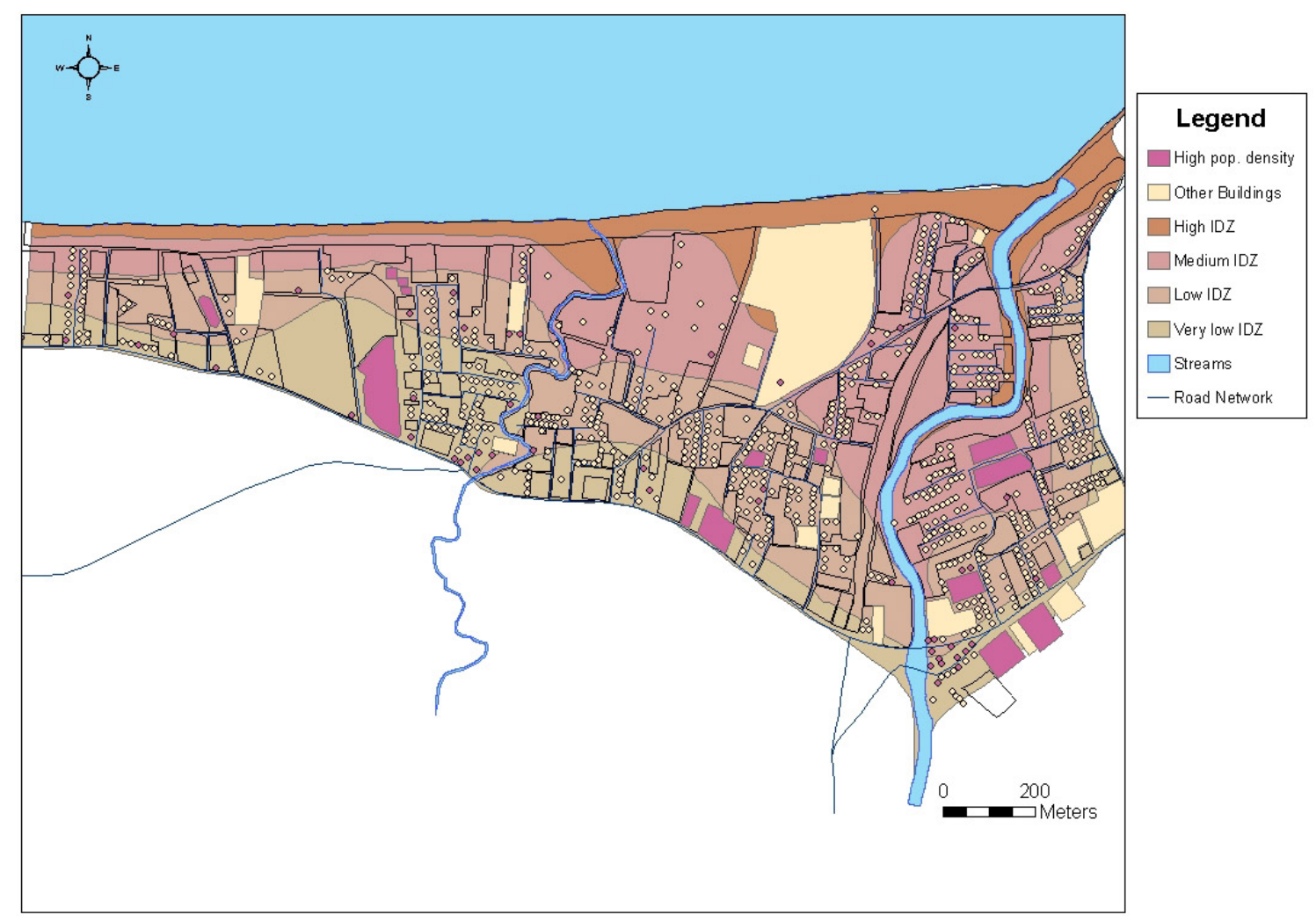

Fig. 6. The population density within the study area during the day in the winter. 


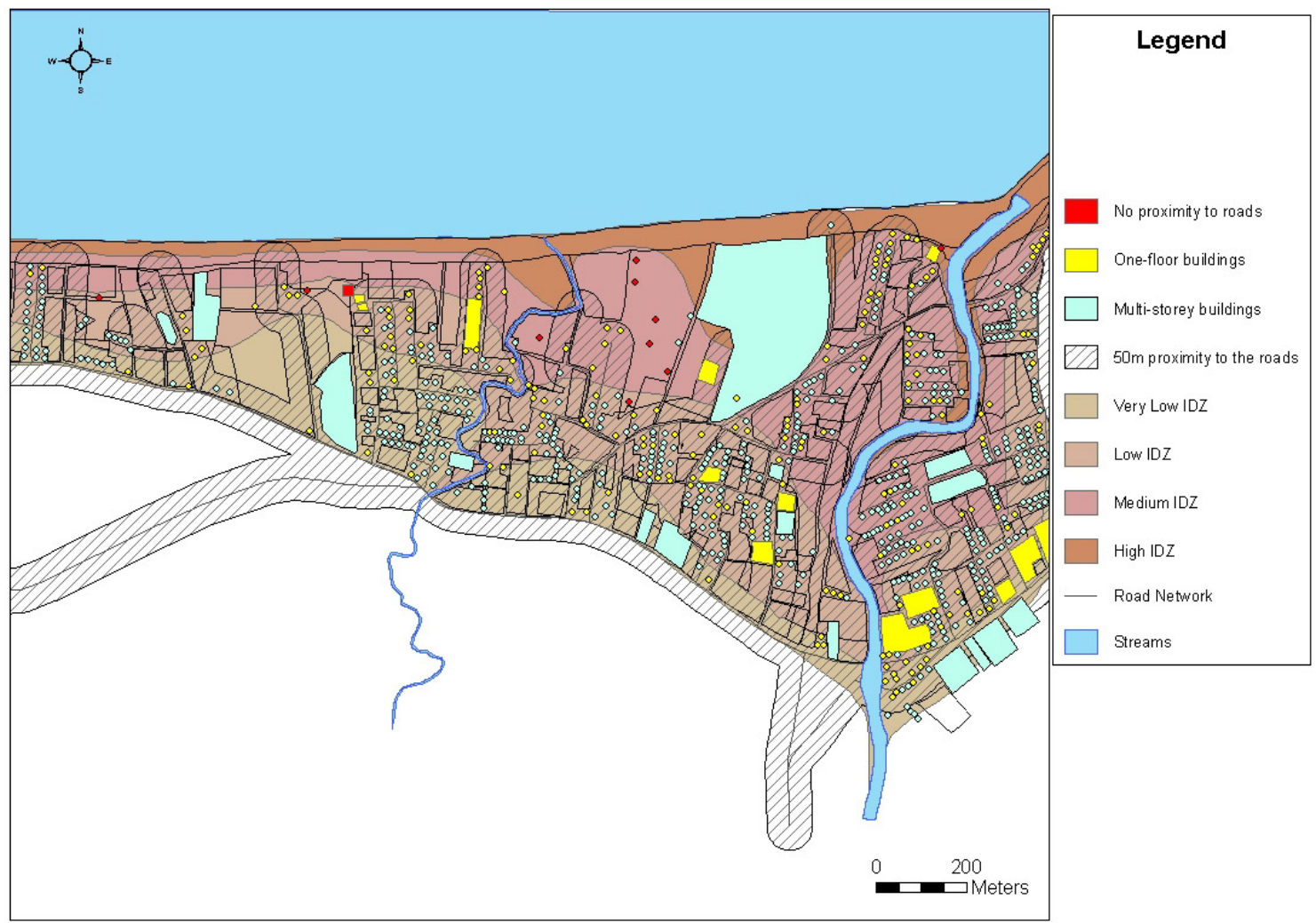

Fig. 7. Map showing the proximity of one-floor buildings to the road network of the study area.

business activity. Various parameters within the primary database could be analysed together and a thematic map of potential losses determined in the form of a catastrophe model. Such a map could be a useful tool for establishing premium levels (Garrad, pers. comm).

\section{Discussion and conclusions}

It may be asked why such a detailed study as we have described, should be undertaken? The answer to this question includes the facts: (1) that historical records show that tsunami present a serious hazard; (2) that the likely impacts of future tsunami will be much greater than in the past because of the recent development of many coastal areas of Greece and; (3) that there will be very limited time available for early warning or evacuation because the distance between points of origin and impact sites are relatively short (circa 1 to $30 \mathrm{~min}$ ). Tsunami arrival times vary according to the source of the tsunami. According to Yokohama (1978) the tsunami caused by the prehistoric eruption of Santorini volcano reached Herakleio in $25 \mathrm{~min}$, whereas the AD1956 tsunami generated by an earthquake south of the island of Amorgos reached the port of Herakleio 20 min after the main earthquake (Galanopoulos, 1957). In addition, because of the density and importance of the present coastal infrastructure (harbours, tourist centres and archaeological sites), it would be unrealistic for local and national government to prevent or even limit building and occupation of the coastal environment. It would also be unrealistic in terms of economic costs, to reinforce every building within the tsunami flood hazard zone. Lastly, it would not be possible to construct large hard engineered coastal barriers (breakwaters, walls and revetments) along significant stretches of Greece's coastline because of the negative aesthetic impacts that such structures would have on the local environment. Therefore, it is of vital importance that disaster managers and emergency planners have detailed information on which buildings, structures, infrastructural units and groups of people are particularly vulnerable to tsunami impacts. When such data are available, cost effective mitigation measures may be developed and applied.

By developing and applying the approach we have described, the usefulness of the GIS is demonstrated. The principle advantage of using GIS for tsunami disaster management is that a dynamic database is generated rather than a series of static maps. This primary database may be used in a number of different ways according to the requirements of the end-user. Additionally, the raw data within the attribute tables may be updated very easily, the operating scenario may be modified and the study area (scale) may be enlarged or reduced. Furthermore, each attribute may be analysed individually or in any combination which should help to identify problematic areas. The database may be extended to include new attributes and much of the base data would be useful for the investigation of vulnerability associated with other 


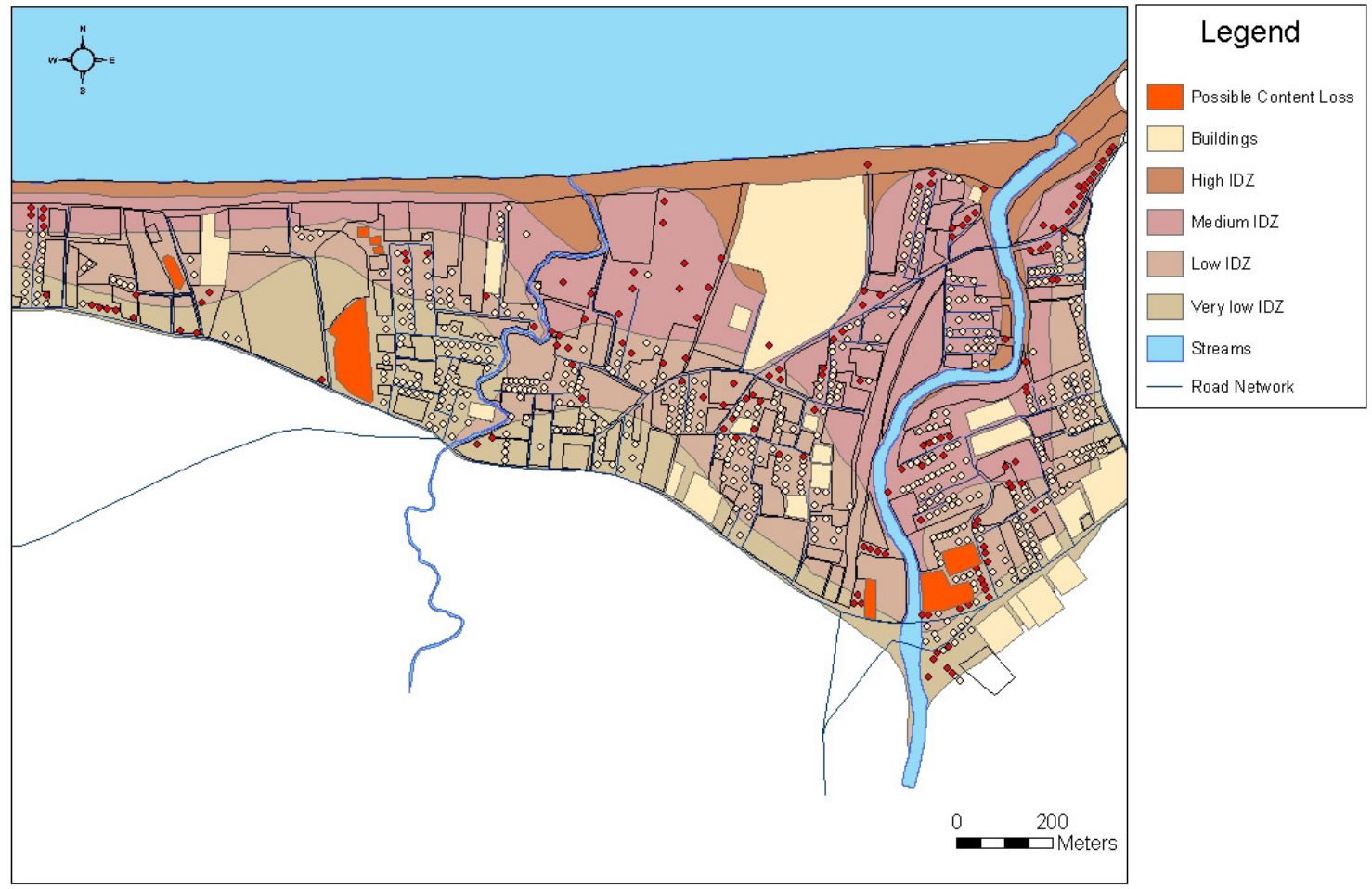

Fig. 8. Map showing buildings that will experience content loss due to tsunami flooding.

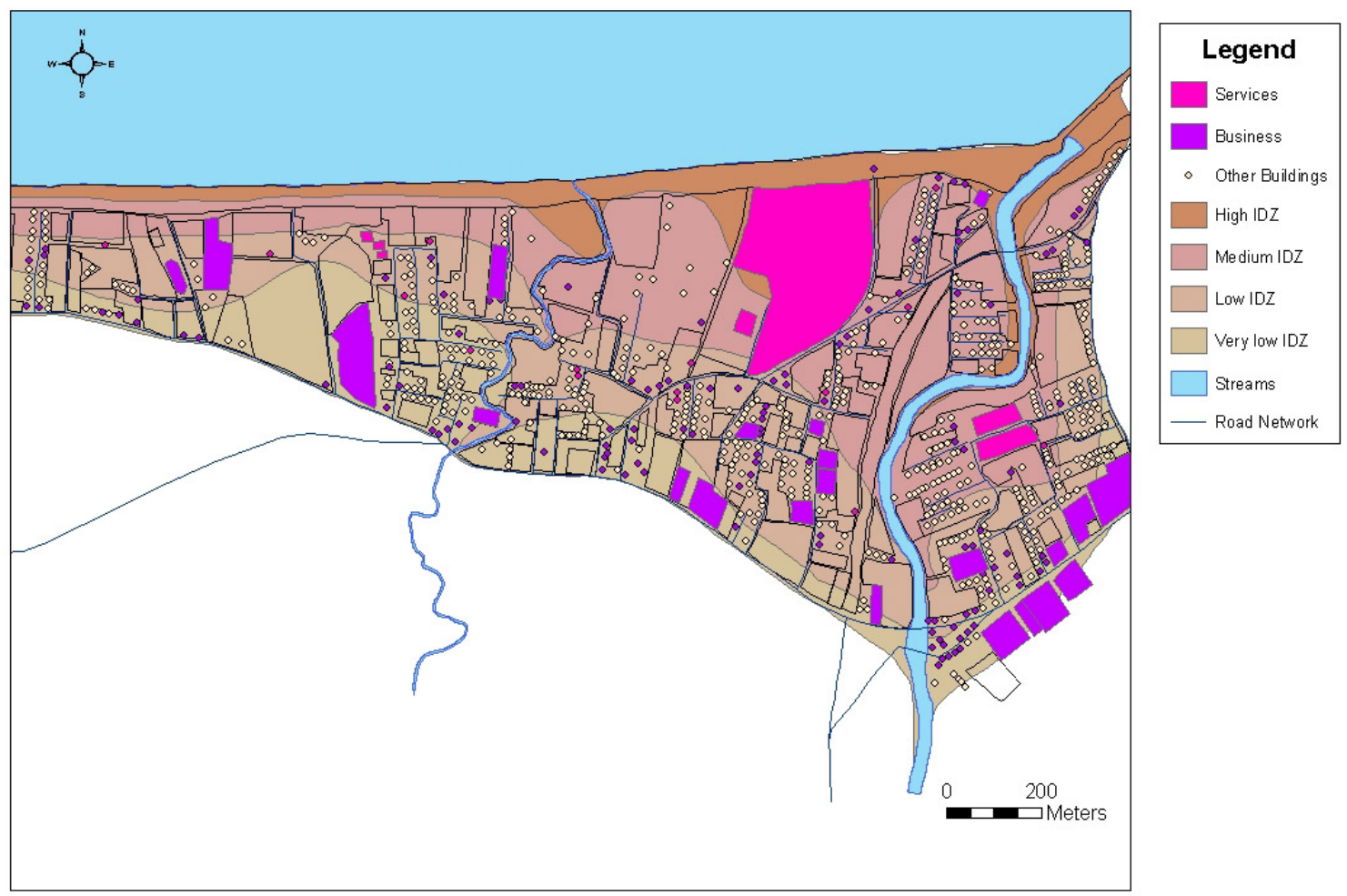

Fig. 9. The distribution of businesses and services within the study area. 
hazards such as floods or earthquakes. It can be seen from the figures, that the final maps are easy to read and they may also be displayed in different formats and may be illustrated with audio-visual media such as video clips and photographs of the area.

The next step in the development and refinement of our approach will be to gather data on the build and rebuild costs for building units of different construction types and uses. This information will then be integrated within the GIS primary database so that: (1) local planning authorities may make decisions about the level of acceptable risk in relation to permitting development in different tsunami flood zones and; (2) insurance companies have useful spatial data relating to potential maximum claims for building damage within the flood zone.

Tsunami pose a major threat to many coastal areas of the world and large tsunami may lead to significant loss of life as well as to destruction of coastal infrastructure and business activity. Historical records demonstrate that coastal areas of Greece are at risk from tsunami inundation. Disaster managers and emergency planners must therefore, develop and apply appropriate and effective disaster management plans and measures. To do this, detailed information is needed regarding both the spatial and temporal vulnerability of the area at risk. Previous tsunami risk assessment methodologies have either assumed uniform vulnerability within the tsunami flood zone or are not fluid enough in their approach to determine a pattern of vulnerability under different inundation scenarios. We have outlined an approach that allows a dynamic assessment of tsunami vulnerability both spatially and temporally. This approach may be easily transferred to other at risk areas and the information within the primary database may be used by multiple end-users. Such an approach should avoid costly socio-economic mistakes, as limited resources may be more effectively targeted.

Acknowledgements. G. Papadopoulos is thanked for providing local site information in the field and scientific guidance. Funding for this research was provided by Coventry University. R. Blong and an anonymous referee are thanked for making very helpful comments on an earlier draft of this paper which have substantially improved the text.

\section{References}

Alexander, D.: Confronting Catastrophe, Terra Publishing, 282 pp., 2000.

Ambraseys, N. N.: Data for the investigation of seismic sea waves in the eastern Mediterranean, Bulletin of the Seismological Society of America, 52, 895-913, 1962.

Antonopoulos, J.: Data for the investigation of seismic sea waves, Annali di Geofisica, 33, 1-5, 141-229, 1980.

Bush, D. M., Neal, W. J., Young, R. S., and Pilkey, O. H.: Utilization of geoindicators for rapid assessment of coastal-hazard risk and mitigation, Ocean and Coastal Management, 42, 647-670, 1999.
Camilleri, D. H.: Vulnerability of buildings in Malta to earthquake, volcano and tsunami hazard, The Structural Engineer, 77, 22, 25-31, 1999.

Duncan, A. M., Dibben, C., Chester, D. K. and Guest, J. E.: The 1928 eruption of Mount Etna volcano, Sicily and the destruction of the town of Mascali, Disasters, 20, 1, 1-20, 1996.

Dominey-Howes, D. T. M.: Assessment of tsunami magnitude and implications for urban hazard planning in Greece, Disaster Prevention and Management, 7, 3, 176-182, 1998.

Dominey-Howes, D. T. M.: Documentary and geological records of tsunamis in the Aegean Sea region of Greece and their potential value to risk assessment and disaster management, Natural Hazards, 25, 195-224, 2002.

Dominey-Howes, D. T. M., Papadopoulos, G. A., and Dawson, A. G.: Geological and historical investigation of the AD1650 Mt Columbo (Thera Island) eruption and tsunami, Natural Hazards, 21, 83-96, 2000.

ESRI: Understanding GIS: the ARC/INFO Method, Environmental Research Institute, Inc., 1990.

ESRI: Challenges for GIS in Emergency Preparedness and Response, An ESRI White Paper, 2000

European Commission: Housing Statistics in the European Union 2000, 83 pp., 2000.

Fischer, H. W., Scharnberger, C. K., and Geiger, C. J.: Reducing seismic vulnerability in low to moderate risk areas, Disaster Prevention and Management, 5, 4, 5-18, 1996.

Fritzalas, C. I. and Papadopoulos, G. A.: Volcanic risk and urban planning in the region of Santorini volcano, South Aegean, Greece, in: Proceedings of the international Symposium on the engineering Geology and ancient Works, monuments and Historical Sites, edited by Marinos, P. G. and Koukis, G. C., Preservation and Protection, 1321-1327, 1988.

Fytikas, M., Kolios, N. and Vougioukalakis, G.: Post-Minoan volcanic activity on the Santorini volcano. Volcanic Hazard and risk, forecasting possibilities, in: Thera and the Aegean World III, edited by Hardy, D., Keller, J., Galanopoulos, V. P., Flemming, N. N., and Druitt, D. H., Earth Sciences, 2, 183-198, 1990.

Galanopoulos A. G.: The seismic wave of 9 July 1956, Praktika Akadimias Athinon, (in Greek) 32, 90-101, 1957.

Ganas, A., Nikolaou, E., Dermentzopoulos, Th., and Papadopoulos, G. A.: A GIS for tsunami risk mapping and management. NATO Adv. Workshop - Underwater Ground Failures on Tsunami Generation, Modeling, Risk and Mitigation, Istanbul, 23-26 May 2001, 249-252.

Goldsmith, P., Barnett, A., Goff, J., McSaveney, M., Elliot, S., and Nongkas, M.: Report of the New Zealand reconnaissance team to the area of 17 July 1998 tsunami at Sissano Lagoon, Papua New Guinea, Bulletin of the New Zealand Society for Earthquake Engineering, 32, 2, 102-118, 1999.

Hebenstreit G. T. (Ed): Tsunami Research at the End of a Critical Decade, Kluwer Academic Publishers, 282 pp., 2001.

Kawata, Y., Bension, B. C., Borrero, J. C., Borrero, J. L., Davies, H. L., de Lange, W. P., Imamura, F., Letz, H., Nott, J., and Synolakis, C. E.: Tsunami in Papua New Guinea was as intense as first thought, EOS, Transactions, American Geophysical Union, 80, 9, 101, 104-105, 1999.

Maramai A. and Tinti S.: The 3rd June 1994 Java Tsunami: A PostEvent Survey of the Coastal Effects, Natural Hazards, 15, 31-49, 1997.

Papadopoulos, G. A.: A tsunami catalogue of the area of Greece and the adjacent seas, Institute of Geodynamics, National Observatory of Athens, Publication number 8, 17 pp., 1998. 
Papadopoulos, G. A. and Chalkis, B. J.: Tsunamis observed in Greece and the surrounding area from Antiquity up to the present times, Marine Geology, 56, 309-317, 1984.

Papadopoulos, G. A. and Dermetzopoulos, T.: A tsunami risk assessment pilot study in Heraklion, Crete, Natural Hazards, 18, 91-118, 1998.

Papazachos, B. C. and Papazachou, C.: The Earthquakes of Greece, Ziti Editions, Thessaloniki, 1997.

Papazachos, B. C., Koutitas, C., Hatzidimitriou, P. M., Karakostas, B. C., and Papaioannou, C. A.: Tsunami Hazard in Greece and the surrounding area, Annales Geophysicae, 4B, 1, 79-90, 1986.

Scholten, J. and Stillwell, C. H.: Geographic Information Systems: the emerging requirements, in: Geographical Information systems for Urban and Regional Planning, edited by Scholten, J. and Stillwell, C. H., 3-15, 1990.

Shimamoto, T., Tsutsumi, A., Kawamoto, E., Miyawaki, M, and Sato, H.: Field survey report on tsunami disasters caused by the 1993 Southwest Hokkaido earthquake, Pure and Applied Geophysics, 144, 3/4, 665-692, 1995.

Shuto, N. and Matsutomi, H.: Field survey of the 1993 Hokkaido Nansei-Oki earthquake tsunami, Pure and applied Geophysics, 144, 3/4, 649-665, 1995.

Siebert, A.: Tools for Risk and Catastrophe Assessment in the In- surance Industry, in: 20th Annual ESRI International User conference Proceedings 26-30 June, San Diego, USA, 2000.

Solomon, S. M. and Forbes, D. L.: Coastal hazards and associated management issues on South Pacific islands, Ocean and Coastal Management, 42, 523-554, 1999.

Soloviev, S. L.: Tsunamis, The assessment and the mitigation of earthquake and risk, UNESCO, 118-143, 1978.

Soloviev, S. L., Solovieva, O. N., Go, C. N., Kim, K. S., and Shchetnikov, N. A.: Tsunamis in the Mediterranean Sea 2000BC 2000AD, Kluwer Academic Publishers, 237pp., 2000.

Synolakis, C. E., McCarthy, D., Titov, V. V., and Borrero, J.: Evaluating the tsunami risk in California, California and the World Ocean, 1225-1236, 1998.

Tsuji, Y., Matsutomi, H., Imamura, F., Takeo, M., Kawata, Y., Matsuyama, M., Takahashi, T., and Harjadi, P.: Damage to coastal villages due to the 1992 Flores Island earthquake tsunami, Pure and Applied Geophysics, 144, 3/4, 481-524, 1995.

Wood, N. and Stein, D.: A GIS-based vulnerability assessment of Pacific Northwest ports and harbours to tsunami hazards, in: ITS 2001 Proceedings, Session 1, 1-13, 367-374, 2001.

Yokoyama, I.: The tsunami caused by the prehistoric eruption of Thera, in: Thera and the Aegean World I, 2nd Scientific Congress, Santorini, Greece, 1978. 